* Doutora e Mestre em Direito Civil Comparado pela Pontifícia Universidade Católica de São Paulo (PUC-SP). Professora do Programa de Mestrado e Graduação em Direito da Universidade de Marília (UNIMAR). E-mail: mariana@nbsadvogados. com.br.

** Pós-Doutoranda na Faculdade de Direito da Universidade de São Paulo (USP). Doutora em Direito das Relações Econômicas e Internacionais pela Pontifícia Universidade Católica de São Paulo (PUC-SP). Mestre em Políticas Públicas e Processo pela Faculdade de Direito de Campos (FDC). Professora Adjunta I do Programa de Mestrado em Direito e Graduação da Universidade Federal do Mato Grosso do Sul (UFMS). E-mail: livia.gaigher@uol. com.br.

\section{FUNÇÃO SOCIAL E SOLIDÁRIA DA EMPRESA NA DINÂMICA DA SOCIEDADE DE CONSUMO}

\author{
COMPANIES SOCIAL AND SOLIDARITY DUTIES \\ IN A CONSUMERISTIC SOCIETY
}

\author{
* Mariana Ribeiro Santiago \\ **Livia Gaigher Bósio Campello
}

Resumo: O presente artigo visa analisar a evolução do comércio no direito brasileiro, no contexto das transformações do Estado moderno, que repercutem diretamente em matéria de função social. Nesse intuito, partimos das patologias do consumo na sociedade moderna, atravessando as diferentes implicações nas questões sociais, culminando com o estudo da evolução da ideia de empresa, de instrumento do liberalismo e do individualismo, atravessando as diferentes limitações jurídicas que lhe foram impostas. Em conclusão, verificamos que o papel da empresa deve ser ampliado, no contexto da sociedade de consumo, para auxiliar no combate ao consumismo e da alienação individual.

Palavras-chave: Empresa. Função social. Sociedade de consumo.

Abstract: This paper analyses the evolution of commerce based on Brazilian law and its foundation has been built on the modern State's transformations, and thus, had a direct impact on its social duty. From modern society's pathological consumerism, which has many social implications, to the growing concept of companies, which has passed through many legal constraints, and was known for being an instrument of economic liberalism and individualism. This paper will also show that the roles, which companies play in our consumeristic society, ought to be expanded in the fight against consumerism and social alienation.

Keywords: Companies. Social duty. Consumeristic society.

Como citar: SANTIAGO, Mariana Ribeiro; CAMPELLO, Livia Gaigher Bósio. Função social e solidária da empresa na dinâmica da sociedade de consumo. Scientia Iuris, Londrina, v. 20, n. 1, p.119-143, abr. 2016. DOI: 10.5433/2178-8189.2016v20n 1p119. ISSN: 2178-8189. 


\section{INTRODUÇÃO}

O liberalismo individualista, instaurado pela Revolução Francesa como reação ao Estado limitador e absolutista, que dominou a Idade Média, ao limitar ao máximo a interferência estatal, consolidou o Estado liberal e o século XIX se tornou o momento histórico ideal para cristalizar essa ideologia (RODRIGUES, 2002, p. 5-6).

De acordo com Laski (1973, p. 117), a França setecentista era uma sociedade em fermentação, na qual a pressão das novas idéias era inexaurível, e, em nome desse ideário, desafiava-se o ancien régime, e todos os gênios desse período estavam do lado das novidades. A ideologia individualista tornou-se a pedra angular da consolidação do regime capitalista de produção.

Ocorre que, ao longo do Século XX, a sociedade brasileira, assim como todo o mundo, experimentou incontáveis transformações, sendo estas históricas, culturais, sociais, políticas, econômicas, jurídicas etc., as quais expuseram todas as mazelas do pensamento liberalista e, consequentemente, a insuficiência desta ideologia para regência da "nova sociedade".

O Estado social moderno surgiu, exatamente, em decorrência da constatação da falsidade das premissas do Estado liberal: liberdade e igualdade entre os homens. Essa compreensão da desigualdade de fato, que existe entre os homens, levou à formulação do princípio da especialidade, contido no princípio da isonomia, prevendo o tratamento desigual dos desiguais, para que se possa obter, dessa forma, uma igualdade substancial.

No Brasil, o Estado social foi inaugurado com a Constituição de 1934 e está bem delineado na Constituição de 1988, compreendendo-se essas constituições como constituições sociais, uma vez que regulam a ordem econômica e social para além do que pretendia o Estado liberal (LÔBO, 2003, p. 12-13).

A Constituição Federal de 1988 materializa a noção de limitação da iniciativa privada e da propriedade, o que também foi incorporado pelo atual Código Civil, ao tratar, expressamente, da função social da propriedade e dos contratos.

Instituto correlato à função social do contrato, e também à função social da propriedade, é o da função social da empresa, embora este último não tenha recebido menção no Código Civil. Na realidade, esses três princípios 
são aplicações do princípio da socialidade a áreas específicas do direito, daí a conexão entre eles.

Muito já se tratou na doutrina acerca do princípio da função social da empresa, na tentativa de se precisar o seu alcance e as responsabilidades que implica para a empresa. Todavia, problemática nem tanto explorada é a sua aplicação no contexto da sociedade de consumo, com todas as suas peculiaridades e urgências, enquanto fenômeno social, que demanda abordagem interdisciplinar.

A qualidade de consumidor é inerente ao ser humano, sendo que o consumo, enquanto fenômeno, não é uma preocupação recente para a humanidade, precedendo o advento do que Bauman (2007, p. 109) denominou de "variedade líquida" da modernidade.

Muitos dos comportamentos típicos dos consumidores modernos, todavia, ainda que deletérios, tornaram-se tão habituais que os seus membros não alcançam a consciência do impacto causado na vida privada e na esfera social, perdendo-se no que os psicólogos denominam de "cárcere de consumo" (BOTSMAN; ROGERS, 2011, p. 5-6).

Diante disso, questiona-se: a função social da empresa pode ser compreendida como um instrumento de combate ou minimização das patologias da sociedade de consumo? Até que ponto a empresa é responsável ou possui tal papel? É adequada a postura de vitimização do consumidor em todo esse contexto?

O panorama ora noticiado justifica o estudo aprofundado do princípio da função social da empresa, dentro da perspectiva de uma sociedade de consumo, com o objetivo oferecer subsídios para se balizar a atividade empresarial, verificando opções de negócios mais equilibradas e responsáveis, em sintonia com as exigências da pós-modernidade.

Para a obtenção dos resultados almejados pelo trabalho, utilizamos a pesquisa bibliográfica, abrangendo obras especializadas na teoria da empresa, nos princípios do direito comercial e na matéria do consumismo. $\mathrm{O}$ método de abordagem seguido foi o dialético jurídico, abrangendo o fenômeno, fato concreto e a teoria, de forma simultânea, buscando o resultado com o confronto entre os dois.

\section{CULTURA E SOCIEDADE DE CONSUMO}


O homo consumericus, na expressão de Lipovetsky (2007, p. 128), enfrenta, do ponto de vista individual e psicológico, problemas crescentes, a exemplo da exploração do mais forte pelo mais fraco, patologia característica nas contratações de massa, onde se prima pela despersonalização do contratante e padronização das cláusulas contratuais, limitando-se ao extremo a autonomia privada do hipossuficiente técnico-econômico.

No Brasil, o consumidor está, em tese, juridicamente protegido pela incidência do Código de Defesa do Consumidor, o que implica no reconhecimento da desigualdade entre as partes contratantes $\left(\mathrm{CDC}\right.$, art. $\left.4^{\circ}\right) \mathrm{e}$ consequente proteção ao hipossuficiente, através das seguintes ferramentas, entre outras: nulidade de cláusulas abusivas (CDC, $6^{\circ}, \mathrm{IV}, 39$, V, e 51 , IV e $\left.\S 1^{\circ}, \mathrm{III}\right)$; impossibilidade de renúncia de garantias pelo consumidor (CDC, $51, \mathrm{I})$; inversão do ônus da prova em favor do consumidor (CDC, $6^{\circ}$, VIII); possibilidade de revisão contratual $\left(\mathrm{CDC}, 6^{\circ}, \mathrm{V}\right)$; responsabilidade civil objetiva do fornecedor (CDC, 12 e 14), com exceção para os profissionais liberais, os quais deverão responder apenas no caso de culpa; solidariedade na reparação dos danos causados ao consumidor (CDC 18,19, 25, §2 $)$; desconsideração da personalidade jurídica (CDC, 28).

A par da proteção jurídica, a sensação que se tem sobre o consumidor é a de que não necessariamente as pessoas que compram e mantêm mais bens materiais estão mais satisfeitas com as suas vidas, ou mais felizes. Pelo contrário. Problemas como depressão, ansiedade, insônia, obesidade e doenças cardíacas se mostram em crescimento alarmante, desde a década de 80 (BOTSMAN; ROGERS, 2011, p. 14).

Trata-se de uma situação extremamente contraditória, se pensarmos que trabalhamos tão duro para comprar coisas e, já num momento seguinte, não conseguimos mais viver com elas e, ao mesmo tempo, não podemos nos separar delas, sem ao menos nos perguntarmos qual a verdade sobre o motivo pelo qual temos tantas coisas (BOTSMAN; ROGERS, 2011, p. 13).

Todavia, como ressalta Bauman (2007, p. 109), mostra-se profundamente ineficiente e equivocado examinar-se a lógica do consumo como uma atividade individual e solitária no intuito de se compreender o panorama do consumo atual, fazendo-se necessário focar na verdadeira novidade, qual seja, a sua natureza basicamente social, no ambiente da sociedade de consumidores, e apenas secundariamente na seara psicológica ou comportamental.

Nas palavras de Baudrillard (2010, p. 264), 
O consumo constitui um mito. Isto é, revela-se como palavra da sociedade contemporânea sobre si mesma; é a maneira como a nossa sociedade se fala. De certa maneira, a única realidade objetiva do consumo é a ideia do consumo, a configuração reflexiva e discursiva, indefinidamente retomada pelo discurso quotidiano e pelo discurso intelectual.

A sociedade de consumo está calcada na ideia de satisfação dos desejos humanos. Tal promessa, contudo, mostra-se sedutora apenas enquanto o desejo permanece irrealizado e o que se torna permanente é, de fato, a insatisfação (BAUMAN, 2007, p. 106).

A insatisfação se instala a partir do momento em que os produtos, logo após adquiridos, são depreciados e desvalorizados pelo próprio mercado ou, ainda, despertam novos desejos, por novos produtos. A "necessidade" torna-se, assim, compulsão ou vício (BAUMAN, 2007, p. 106-107).

Na lição de Bauman (2007, p. 108),

Para que a busca de realização possa continuar e novas promessas possam mostrar-se atraentes e cativantes, as promessas já feitas precisam ser quebradas, e as esperanças de realiza-las, frustradas. Um mar de hipocrisia se estendendo das crenças populares às realidades da vida dos consumidores é condição sine qua non para que uma sociedade de consumidores funcione apropriadamente. Toda promessa deve ser enganosa, ou pelo menos exagerada, para que a busca continue.

A partir do momento em que não os bens, mas a imagem desses bens se torna acessível a toda a sociedade, restam caracterizados os indícios da cultura de consumo. Todo um contexto de imagens e símbolos passam a ser criados e recriados acerca dos bens, o que reflete em novas formas de comportamento, no modo de sentir e pensar de grande parcela da sociedade ocidental (TASCHNER, 2009, p. 52).

A expressão "cultura de consumo" enfatiza a importância do mundo das mercadorias e seus princípios de estruturação para a compreensão da sociedade 
contemporânea, dentro de um foco duplo, que verifica a dimensão cultural da economia, pela utilização de bens materiais como símbolos comunicadores, e a economia dos bens culturais, de acordo com os princípios de mercado (oferta, demanda, acumulação de capital, competição e monopolização), operando na esfera dos estilos de vida (FEATHERSTONE, 1995, p. 121).

Nesse contexto, a cultura de consumo estimula o jogo das diferenças, pregando que estas precisam ser reconhecidas e legitimadas socialmente. Como consequência, a alteridade total e a individualidade total tendem a ser irreconhecíveis (FEATHERSTONE, 1995, p. 124).

Pode-se afirmar, nessa linha, que a era do consumo, calcada na produtividade acelerada sob o signo do capital, representa igualmente a era da alienação radical. A lógica da mercadoria predomina, ao regular a cultura inteira, desde os processos de trabalho à questão da sexualidade. Passa-se a crer que tudo pode ser espetacularizado, orquestrado em imagens, consumível (BAUDRILLARD, 2010, p. 261).

Em resumo, o processo generalizado de consumo, transmutado em espetáculo, atinge a imagem e a própria alma do homem. O ser individual e suas reflexões restam abolidos em face da emissão e da recepção de signos. Ao homem do consumo não interessam as suas próprias necessidades e a sua própria imagem, perfazendo-se em imagem dos signos que ordena. A sociedade pensa e fala como sociedade de consumo, e, na medida em que consome, consomese em ideia, da qual a publicidade é o hino fundamental (BAUDRILLARD, 2010, p. 261-262, 264).

A sociedade de consumidores transforma-se, assim, em algo maior do que a soma total dos indivíduos consumidores. É uma sociedade que, perigosamente, julga e avalia seus membros principalmente por suas capacidades consumeristas, sua conduta de consumo (BAUMAN, 2007, p. 109).

Nesse sentido, a expressão "sociedade de consumidores" verbaliza mais do que a postura dos seus membros de gastar tempo e esforços visando ampliar seus prazeres, refletindo a percepção de que a política de vida dos indivíduos tende a ser remodelada com base nos meios e objetos de consumo, segundo as linhas da síndrome consumista (BAUMAN, 2007, p. 109).

"Necessitando" consumir para definir o seu papel na sociedade, para alcançar o padrão pregado pela cultura de consumo, os indivíduos se lançam em aquisições impensadas, consequência de uma avaliação deturpada das suas possibilidades e má administração das suas finanças, o que já produz efeitos na 
economia do país e na questão da sustentabilidade.

A abundância dos bens de consumo, símbolo do capitalismo moderno, já é objeto de críticas que alçam o consumismo como um dos principais problemas da sociedade moderna, repercutindo fortemente na crise ambiental. Tratar do consumismo passou a significar também uma contribuição para a construção de uma sociedade mais sustentável (PORTILHO, 2010, p. 67).

A incorporação das questões relacionadas ao consumo aos crescentes movimentos sociais, como o ecológico, acendeu o debate sobre o consumo ambientalmente consciente que, posteriormente, evoluiu para a ideia de consumo social e politicamente responsável. O objetivo é colaborar para que a soberania do consumidor, propagada pelo neoliberalismo, converta-se em cidadania do consumidor, instrumento de ativa prática social, política e ecológica (PORTILHO, 2010, p. 218).

Toda essa discussão demonstra que a organização individualista do consumo desconecta os membros da sociedade enquanto cidadãos, repercutindo na questão da solidariedade. Tornam-se cada vez mais necessária a criação de redes de intercâmbio de informação e aprendizagem com foco nas práticas de consumo enquanto ferramenta para o exercício da cidadania (PORTILHO, 2010, p. 218).

De fato, a busca de alternativas para o consumismo tem repercussão na questão ambiental. Todavia, não se pode olvidar que as matérias da sustentabilidade e da solidariedade extrapolam tal viés, com claro impacto em questões como desenvolvimento social e economia.

Segundo pesquisas realizadas pelo Instituto Akatu, a terra precisaria ter $50 \%$ (cinquenta por cento) mais recursos para sustentar o padrão de consumo atual $^{1}$. Já a Organização das Nações Unidas para a Agricultura e alimentação (FAO) constatou e alertou que, ao final de 2009, o número de vítimas da fome ultrapassaria a marca de um bilhão de pessoas. Tais dados, confrontados, demonstram um padrão de consumo acima das necessidades, a par de uma ausência assustadora de itens básicos de sobrevivência, como alimento, situação a gerar, fora de dúvida, um contexto de desenvolvimento social preocupante (SOARES-BAPTISTA, 2010, p. 363).

Por outro lado, o superendividamento se mostra, cada vez mais, uma

Informação obtida em 25 de agosto de 2013, no site: http://www.akatu.org.br/Temas/Sustentabilidade/ Posts/Terra-precisaria-ter-50-mais-recursos-para-sustentar-padrao-de-consumo-atual. 
realidade na sociedade brasileira. Segundo Marques (2006, p. 256), trata-se uma "impossibilidade global do devedor-pessoa física, consumidor, leigo e de boa-fé, de pagar todas suas dívidas atuais e futuras de consumo".

O Instituto Brasileiro de Geografia e Estatística (IBGE) divulgou, que, em 2012, 14,1\% das famílias brasileiras estavam superendividadas. Já o Instituto de Pesquisa Econômica Aplicada (IPEA) informou que 92,9\% dessas famílias não planejam tomar crédito e 31,6\% das contas estão em atraso. Dados alarmantes como estes fazem com que os economistas afirmem que distorções no sistema de intermediação colocam em risco a oferta saudável de crédito, gerando, consequentemente, atraso no crescimento nacional ${ }^{2}$.

Merece menção, ainda, dentro de uma perspectiva geral, o processo de globalização, enquanto elemento colaborador na alteração da forma como o consumidor tem agido na modernidade. Como consequência de todo esse quadro, fora de dúvida, criaram-se, perigosamente, independentemente dos seus efeitos deletérios, novas tradições de consumo.

No que diz respeito às novas tradições do consumo, acreditamos que a corrida desenfreada pela riqueza material vem causando uma exclusão das necessidades sociais básicas, atreladas ao convívio familiar e comunitário, relações pessoais e responsabilidade social. O prejuízo de toda essa comunicação, que já se nota bastante grave na era do hiperconsumismo, faz com que alguns críticos nos identifiquem como uma sociedade "autista". Tais demandas, de fato, não podem ser supridas através de processos de compra e acúmulo de bens (BOTSMAN; ROGERS, 2011, p. 33).

Todavia, embora já seja possível enxergar que a desordem do hiperconsumismo foi impulsionada por uma crença de que o dinheiro é o grande gerador da felicidade, existem experiências concretas atualmente que nos permitem concluir que este distúrbio pode ser consertado (BOTSMAN; ROGERS, 2011, p. 33).

O reconhecimento desse novo paradigma permite afirmar que o consumismo pode florescer em versões diferentes, de maneira "não tradicional", com um novo papel. Segundo Giddens (2007, p. 54-55),

É inteiramente racional reconhecer que as tradições são

\footnotetext{
${ }^{2}$ Informação obtida em 25 de agosto de 2013, no site:

http://www.ipea.gov.br/portal/index.php?option=com_content\&view=article\&id=14604.
} 
necessárias numa sociedade. (...) As tradições são necessárias e persistirão sempre, porque dão continuidade e forma à vida. (...) A tradição pode muito bem ser defendida de uma maneira não tradicional - e este deveria ser o seu futuro. Ritual, cerimonial e repetição têm um importante papel social, algo compreendido e posto em prática pela maioria das organizações, inclusive os governos. As tradições vão continuar a ser apoiadas enquanto puderem ser efetivamente justificadas - não em termos de seus próprios rituais internos, mas mediante a comparação delas com outras tradições ou maneiras de fazer as coisas.

O sistema de consumismo não é um fato fixo da vida moderna, como aparentemente se mostra. Assim, mostra-se firmemente defensável que, da mesma forma que este sistema foi produzido, é possível remodelá-lo, visando à criação um modelo mais saudável e sustentável (BOTSMAN; ROGERS, 2011, p. 33), sendo imprescindível a análise do papel da empresa em todo esse contexto, conforme será exposto a seguir.

\section{A FUNÇÃO SOCIAL DA EMPRESA: PANORAMA ATUAL}

Conforme aludido em sede de introdução, a função social da empresa pode ser atrelada às conquistas do Estado Social, o qual pode ser definido, do ponto de vista do direito, como aquele que acrescentou à dimensão política do Estado liberal a perspectiva econômica e social, limitando e controlando o poder econômico e tutelando os hipossuficientes (LÔBO, 2003, p. 12-13).

De fato, o Estado pode, com justiça, receber a denominação de Estado social quando confere os direitos do trabalho, da previdência, da educação, intervém na economia como distribuidor, dita o salário, manipula a moeda, regula os preços, combate o desemprego, protege os enfermos, em suma, expande sua influência a quase todos os domínios tradicionalmente pertencentes à iniciativa individual. Caracteriza-se pelo intervencionismo, patronagem ou paternalismo (BONAVIDES, 1972, p. 208).

Nesse sentido, podemos citar a lei da usura (impedindo a cobrança de juros extorsivos), a lei do inquilinato (protegendo o inquilino, considerado parte mais fraca no contrato de locação), a lei de luvas (visando proteger o locatário 
especificamente nas locações comerciais), o Código de Defesa do Consumidor (dispensando proteção especial ao consumidor) etc.

A Constituição Federal de 1988 expressa a noção de limitação da iniciativa privada e da propriedade, bem como o ideal da socialidade, , $5^{\circ}$, XXIII e 170, III, quando trata da dignidade da pessoa (art. $1^{\circ}$, III), dos valores sociais do trabalho e da livre iniciativa (art. $1^{\circ}$, IV), da solidariedade social (art. $3^{\circ}, \mathrm{I}$ ), a função social da propriedade (arts. $5^{\circ}$, XXIII, e 170, III),

Assim, o primeiro confronto entre o pensamento liberal e a tendência socializante da época atual ocorreu em detrimento da propriedade, sendo pacífica, atualmente, a concepção de que a propriedade é um direito limitado. Desse entendimento por si só já seria possível deduzir a função social do contrato e da empresa, uma vez que se trata de institutos ligados à circulação da propriedade.

Tendo em vista que a empresa é instrumento legal para o exercício de iniciativas econômicas, nada mais coerente do que reconhecer a função social da empresa, já que a própria Constituição de 1988 estabelece que a livre iniciativa deve ter um valor social.

Se a livre iniciativa é a possibilidade de agir antes de qualquer outro, sem influência externa, como uma expressão da liberdade, o valor social, no caso, significa que essa atividade deve ser socialmente útil e que se procurará a realização da justiça social, do bem-estar social (CRETELLA JR.,1992, p. 140-141).

A previsão expressa, no atual Código Civil, do princípio da função social da propriedade e do contrato vem arrematar esse entendimento, aplicando, especifica e expressamente, os preceitos da justiça social, consolidando entre nós, definitivamente, a visão da autonomia privada limitada.

Nesse sentido, dispõe o Código Civil, em seu art. 421: "a liberdade de contratar será exercida em razão e nos limites da função social do contrato"; e no seu art. 1.228, $\S 1^{\circ}$ : "o direito de propriedade deve ser exercido em consonância com as suas finalidades econômicas e sociais e de modo que sejam preservados, de conformidade com o estabelecido em lei especial, a flora, a fauna e as belezas naturais, o equilíbrio ecológico e o patrimônio histórico e artístico, bem como evitada a poluição do ar e das águas".

O princípio da socialidade é um dos três princípios basilares do novo Código Civil, sendo os outros dois o princípio da eticidade e o princípio da operatividade. Isso é assim, exatamente, em consequência da mudança de visão 
que condenou o individualismo exacerbado à morte.

A socialidade veio substituir o individualismo à medida que o indivíduo voltou a estar encadeado à sua comunidade, confundindo-se com o meio social, o que é próprio da natureza humana, uma vez que o homem é um ser social, para o qual é impossível viver sozinho. A socialidade é uma tendência natural do homem, que vive sempre em grupo e tem o instinto de viver associado a outras pessoas, um verdadeiro impulso comunitário ou grupalista (FERREIRA, 1977, p. 424).

O Código Civil de 2002, a exemplo do Codice Civile italiano, em nome da unidade lógica, procedeu à unificação do direito das obrigações, na esfera civil e na comercial, no que se refere a sua parte geral, de onde se pode concluir que a função social dos contratos também se observa na esfera comercial. $\mathrm{Na}$ realidade, como ressalta Reale (1986, p. 6), essa unificação já se observava há muito tempo na prática, em virtude da antiguidade do Código Comercial.

A unificação do direito das obrigações, entretanto, não é novidade no panorama jurídico nacional, já havia sido proposta no Esboço de Código Civil de Freitas (1864); além do que não segue à risca o modelo italiano, que estende a unificação ao campo do direito do trabalho.

O Código de 2002 revogou a parte primeira do Código Comercial (arts. $1^{\circ}$-456). A parte terceira (arts. 797-913) já havia sido revogada pela Lei de Falência. Em relação ao Código Comercial, atualmente, só está em vigor a sua parte segunda, que trata do comércio marítimo, com exceção do título IX (Do naufrágio e salvados - arts. 731/739), anteriormente revogado pela Lei 7.542/86 (NERY JUNIOR, 2003, p. 405).

A atividade empresarial é, na verdade, uma especificação do direito das obrigações, uma projeção natural e imediata deste. É por essa razão que o direito de empresa (Livro II) surge no Código de 2002 como consequência imediata do direito das obrigações (Livro I) (REALE, 1986, p. 6). É por esse motivo também que se pode falar em função social da empresa.

Por outro lado, como a sociedade é um contrato plurilateral, aplica-se

3 "O acionista controlador deve usar o poder com o fim de fazer a companhia realizar o seu objetivo e cumprir sua função social, e tem deveres e responsabilidades para com os demais acionistas da empresa, os que nela trabalham e para com a comunidade em que atua, cujos direitos e interesses deve lealmente respeitar e atender".

4 "o administrador deve exercer as atribuições que a lei e o estatuto lhe conferem para lograr os fins e no interesse da companhia, satisfeitas as exigências do bem público e da função social da empresa". 
também a ela o art. 421, do Código de 2002, pelo qual os contratos devem se pautar pela sua função social (WALD, 2003, p. 854).

Vale ressaltar, ainda, que a função social da empresa já podia ser deduzida dos arts. 116, parágrafo único ${ }^{3}$, e $154^{4}$, da Lei das Sociedades por Ações (6.404/76), embora se trate de legislação específica apenas sobre uma espécie societária.

Uma vez constatado que o princípio da função social da empresa já se encontrava implícito no nosso ordenamento jurídico desde a Constituição Federal de 1988, pois é decorrência automática da função social da propriedade e do valor social da livre iniciativa, que são imposições da socialidade característica do Estado social, independentemente de não ter sido nomeado no Código Civil, resta agora nos direcionarmos na tentativa de esclarecer o seu conteúdo e contextualizá-lo na sociedade de consumo.

A empresa, em síntese, no sentido econômico, pode ser definida como uma organização de fatores de produção. Está inserida na ordem econômica como agente organizador da atividade produtiva e gestora de propriedades privadas (REQUIÃO, 1978, p. 32).

A esse respeito, vale lembrar a lição de Briz (1966, p. 26), para quem:

[...] la libertad de industria en sentido amplio (como libertad de creación de empresas y libertad de economía) encierra la libertad de competencia, la libertad de contratación, la de producción y la de consumo.

Dessa forma, pode-se afirmar que limitar a empresa através de sua sociabilidade ou função social significa a democratização e moralização do governo da empresa e a realização de uma conduta que atenda aos superiores interesses do país e da sociedade (WALD, 2003, p. 854).

Segundo Bobbio (1990 apud SANTOS, 2002, p. 103), numa analogia entre a sociedade e o organismo humano, função é a "prestação continuada que um determinado órgão dá para a conservação e desenvolvimento, segundo um ritmo de nascimento, crescimento e morte, de todo o organismo, é dizer, do organismo considerado como um todo", de onde se infere a ideia principal de que o poder individual deve ser exercido em proveito de um sistema maior, do conjunto.

De Plácido e Silva (1963, p. 722-723), define função (do latim, fungi), em 
termos gerais, como o direito ou dever de agir, atribuído por lei a uma pessoa, para assegurar o preenchimento de uma missão. Já a palavra "social", como assinala Bonavides (1972, p. 203-204), De Plácido e Silva (1963, p. 722-723), é de grande imprecisão semântica, estando, por isso, sujeita a inúmeras variações de sentido, ao sabor inclusive de determinados preconceitos ideológicos. Esse fator, sem dúvida, dificulta a tarefa de conceituação.

No conceito de Hedemman (1958, p. 26), a palavra social significa "el punto de partida ideológico de la contraposición entre pobres y ricos o, como frecuentemente se dice en la literatura científica, entre los que tienen bienes y los desheredados".

Guedes (2003, p. 351), De Plácido e Silva (1963, p. 722-723), em obra que trata da evolução da funcionalidade primitiva para o atual conceito de função social, afirma que a expressão "função social" significa, abreviadamente, utilidade à sociedade, atendimento ao interesse coletivo.

Maria Helena Diniz (1998) define a função social da empresa como:

O exercício pelo administrador da sociedade por ações das atribuições legais e estatutárias para a consecução dos fins e do interesse da companhia, usando do seu poder de modo a atingir a satisfação das exigências do bem comum. (DINIZ, 1998, p. 613).

No mesmo sentido, Tomasevicius Filho (2003, p. 40) afirma que a função social da empresa constitui um poder-dever por parte do empresário e dos administradores da empresa de harmonizarem as atividades desta com o interesse da sociedade, mediante a obediência de determinados deveres positivos e negativos.

Em resumo, pode-se dizer que a função social da empresa limita a vontade e o interesse dos detentores do capital, substituindo o poder arbitrário do dono da empresa pelo equilíbrio que deve passar a existir entre as forças que cooperam para o desenvolvimento das finalidades empresariais. Trata-se, assim como no caso da função social do contrato, de submeter o interesse particular ao interesse social.

Como instrumento da função social da empresa, costuma-se citar os poderes conferidos à Comissão de Valores Mobiliários - CVM - para intervir assegurando o equilíbrio entre os participantes do mercado, impondo obrigações 
às empresas que têm títulos negociados no mercado de capitais e restringindo a autonomia privada dessas sociedades mercantis, a fim de que não haja prejuízo do acionista minoritário ou do investidor (LAUAND, 2001, p. 236-237).

A Comissão de Valores Mobiliários (CVM), autarquia vinculada ao Ministério da Fazenda, foi criada pela Lei 6.385/76, que dispõe sobre o mercado de valores mobiliários. $\mathrm{O}$ art. $4^{\circ}$, dessa lei, confere a CVM poder disciplinar, poder de polícia e poder normativo. Inclusive, entre as suas atribuições consta a de assegurar a observância de práticas comerciais equitativas no mercado de valores mobiliários (art. $\left.4^{\circ}, \mathrm{VII}\right)$. Anteriormente a essa lei, o Banco central era responsável pela fiscalização do mercado de capitais. Esse dirigismo estatal, vale ressaltar, dá segurança ao investidor e ao mercado de capitais.

O fenômeno da desconsideração da personalidade jurídica da sociedade também é comumente apontado como um reflexo da visão de que o interesse dos sócios da empresa deve ser limitado pelo interesse social, do ponto de vista que a empresa não pode lesar terceiros sob a proteção do escudo de que a personalidade e o patrimônio da pessoa jurídica não se confundem com a personalidade e o patrimônio dos sócios (JUSTEN FILHO, 2000, p. 55-56).

O Código Civil de 2002 estabelece expressamente essa possibilidade de desconsideração da personalidade jurídica no seu artigo $50^{5}$, sendo que tal ideia

\footnotetext{
5 "Em caso de abuso da personalidade jurídica, caracterizado pelo desvio de finalidade, ou pela confusão patrimonial, pode o juiz decidir, a requerimento da parte, ou do Ministério Público quando lhe couber intervir no processo, que os efeitos de certas e determinadas relações de obrigações sejam estendidos aos bens particulares dos administradores ou sócios da pessoa jurídica".

6 "O juiz poderá desconsiderar a possibilidade jurídica da sociedade quando, em detrimento do consumidor, houver abuso de direito, excesso de poder, infração da lei, fato ou ato ilícito ou violação dos estatutos ou contrato social. A desconsideração também será efetivada se houver falência, estado de insolvência, encerramento ou inatividade da pessoa jurídica provocados por má administração".

A publicidade, conforme a definição adotada pelo Código de Defesa do Consumidor, consiste em toda a informação ou comunicação difundida para, direta ou indiretamente, promover junto aos consumidores a aquisição de produtos ou serviços, independentemente do local ou meio de comunicação utilizado, excluindo-se, dessa forma, a propaganda política, regulada em lei eleitoral, e a publicidade governamental, atreladas à difusão de ideias (MARQUES, 2002, p.673).

8 "A proteção contra a publicidade enganosa e abusiva, métodos comerciais coercitivos ou desleais, bem como contra práticas e cláusulas abusivas ou impostas no fornecimento de produtos e serviços".

9 "Art. 37. É proibida toda publicidade enganosa ou abusiva. $\S 1^{\circ}$ É enganosa qualquer modalidade de informação ou comunicação de caráter publicitário, inteira ou parcialmente falsa, ou, por qualquer outro modo, mesmo por omissão, capaz de induzir em erro o consumidor a respeito da natureza, características, qualidade, quantidade, propriedades, origem, preço e quaisquer outros dados sobre produtos e serviços. $\S 2^{\circ}$ E abusiva, dentre outras a publicidade discriminatória de qualquer natureza, a que incite à violência, explore o medo ou a superstição, se aproveite da deficiência de julgamento e experiência da criança, desrespeita valores ambientais, ou que seja capaz de induzir o consumidor a se comportar de forma prejudicial ou perigosa à sua saúde ou segurança. $\S 3^{\circ}$ Para os efeitos deste código, a publicidade é enganosa por omissão quando deixar de informar sobre dado essencial do produto ou serviço".
}

SCIENTIA IURIS, Londrina, v.20, n.1, p.119-143, abr.2016 | DOI: 10.5433/2178-8189.2016v20n1p119 
já estava materializada anteriormente no Código de Defesa do Consumidor, no seu artigo $28^{6}$.

De fato, se o conceito de pessoa jurídica for empregado para fraudar credores, para se furtar de uma obrigação existente, constituir monopólios, entre outras condutas em desvio à aplicação da lei, é possível, no bojo de um processo judicial, prescindir-se da personalidade jurídica, considerando a sociedade como um conjunto de homens que participam ativamente de tais atos, para fins de fazer justiça entre pessoas reais (REQUIÃO, 2002, p. 753).

A proibição à publicidade ${ }^{7}$ enganosa e abusiva, contida nos artigos $6^{\circ}$, $\mathrm{IV}^{8}$, e $37^{9}$, do Código de Defesa do Consumidor (Lei 8.078/1990), também pode ser apontada como uma limitação à atividade da empresa, primando pela sua função social. Tais dispositivos coíbem a captação de consumidores através da utilização publicitária de informações falsas ou que induzam a erro acerca da natureza, características, qualidade, quantidade, propriedades, origem, preço e quaisquer outros dados sobre produtos e serviços, bem como condenam a publicidade discriminatória, que incite à violência, explore o medo ou a superstição, use inexperiência da criança, desrespeite valores ambientais ou induza o comportamento prejudicial ou perigoso à saúde ou segurança do consumidor.

É possível identificar, todavia, alguns dos embates principais para o desenvolvimento do tema da função social da empresa: a dificuldade de compatibilização entre a função social da empresa e o seu objeto, que é uma organização produtora de lucros; bem como o problema de se exigir que as empresas multinacionais e transnacionais tenham, diante da globalização presente, afinidade com os interesses locais, regionais ou nacionais preconizados pela função social da empresa (BITELI, 2000, p. 239).

Esses argumentos, contudo, não são suficientes para se negar a função social da empresa, pois tratam de dificuldades que podem ser observadas no caso dos contratos, que também são usados como instrumento para obtenção de lucro e se inserem por vezes em conflitos culturais, nos casos de contratos internacionais, sem que essas dificuldades diminuam a força do princípio, intimamente relacionado à função social da empresa.

\section{O PAPEL DA EMPRESA NO COMBATE AO CONSUMISMO}

Passada essa síntese geral acerca da função social da empresa, a questão 
que sobrevém, de extrema importância para análise de tal instituto, dentro do quadro da pós-modernidade, é a necessidade de se observar o viés social, ou seja, analisar a empresa no ambiente da sociedade de consumidores e suas especificidades, onde as ações empresariais podem significar perdas em grande escala, para além de um grupo determinado de sócios, contratantes ou consumidores.

No contexto da sociedade de consumo, as empresas estimulam o jogo das diferenças, pregando que estas precisam ser reconhecidas e legitimadas socialmente, operando, assim, na esfera dos estilos de vida, potencializando o fenômeno do consumismo (FEATHERSTONE, 1995, p. 124).

Se a lógica da mercadoria predomina, ao regular a cultura inteira, desde os processos de trabalho à questão da sexualidade, isso requer uma atividade socialmente muito mais responsável por parte da empresa. Pode-se afirmar, nessa linha, que a atividade empresarial que não é socialmente responsável, no contexto da sociedade de consumo, pode induzir ou contribuir para que se instaure uma era da alienação radical, o que muito além de significar um desvio de função social, ofende o princípio da solidariedade social.

Na nossa opinião, tais questões de sustentabilidade social, assim como os casos de sustentabilidade econômica e ambiental, estão ligadas à empresa, mas não tecnicamente sob o viés da função social, esta correlata aos direitos fundamentais de segunda dimensão. Na realidade, trata-se de matéria referente ao princípio da solidariedade social, de magnitude constitucional, por abarcar o aspecto do interesse das gerações futuras e aspectos transnacionais, mais amplos, conexos aos direitos fundamentais de terceira dimensão.

A solidariedade social ingressa no sistema jurídico materializada no art. $3^{\circ}$, I, da Constituição Federal, como marca do Estado democrático de direito, estimulando em cada indivíduo consciência perceptiva do ambiente social, pelo que pode ser considerada como um novo paradigma para o direito, no qual Estado e indivíduo assumem uma aliança, de caráter absolutamente democrático, visando incrementar direitos básicos destes, promoção de políticas de erradicação da pobreza e de redução das desigualdades (CARDOSO, 2010, p. 109, 116, 122 e 151).

Comentando o art. $3^{\circ}$, I, da Constituição brasileira, José Afonso da assevera:

O que a Constituição quer, com esse objetivo fundamental, é 
que a República Federativa do Brasil construa uma ordem de homens livres, em que a justiça distributiva e retributiva seja um fator de dignificação da pessoa e em que o sentimento de responsabilidade e apoio recíprocos solidifique a ideia de comunidade fundada no bem comum. Surge aí o signo do Estado democrático de direito, voltado à realização da justiça social, tanto quanto a fórmula liberdade igualdade e fraternidade o fora no Estado liberal proveniente da Revolução Francesa. (SILVA, 2009, p. 46-47).

Ao tentar precisar o alcance da palavra solidariedade, Lôbo (2009, p. 81) afirma que esta,

[...] como categoria ética e moral que se projetou para o mundo jurídico, significa um vínculo de sentimento racionalmente guiado, limitado e auto-determinado que impõe a cada pessoa deveres de cooperação, assistência, amparo, ajuda e cuidado em relação às outras. A solidariedade cresce de importância na medida em que permite a tomada de consciência da interdependência social.

A solidariedade social realiza-se, então, como um ato complexo, no qual concorrem o Poder Público e a própria sociedade, apontando a Constituição Federal as diretrizes ideológicas, políticas e jurídicas para sua otimização e implementação, ao acolher os princípios da dignidade humana e do pluralismo social e político (DINIZ, 2007, p. 173).

O discurso da solidariedade, dentro de um quadro democrático, implica admitir direitos e deveres nas relações interindividuais, como cooperação e respeito, exigindo uma postura não só do Estado, mas também de cada cidadão em relação a todos os demais, o que vai muito além dos limites impostos às empresas pelo instrumento da função social.

A função social obriga os contratantes a não se afastarem das "expectativas sociais" referentes a um dado negócio, não se desviando para propósitos inúteis ou contrários à coletividade, sob pena de se observar a interferência estatal na readequação do negócio. Impõe, assim, às partes, uma postura negativa de não desrespeitar a sociedade. 
A seu turno, o princípio da solidariedade, que sustenta a função solidária da empresa, possui uma conotação diversa, pois agrega uma ideia de que se deve também colaborar, por meio do negócio, para o desenvolvimento da sociedade, numa perspectiva de auxílio às pessoas, de uma forma positiva, inclusive sob o ângulo das gerações futuras. A função solidária da empresa é aquela que traz uma contribuição valorosa para o desenvolvimento social.

O processo generalizado de consumo, transmutado em espetáculo, atinge a imagem e a própria alma do homem. O ser individual e suas reflexões restam abolidos em face da emissão e da recepção de signos, e a empresa tende a se aproveitar desse processo, contrariando o princípio da solidariedade social, para alavancar os lucros, sendo a publicidade o hino fundamental para tal fim (BAUDRILLARD, 2010, p. 261-262, 264).

A característica principal da publicidade enganosa, segundo o Código de Defesa do Consumidor, é ser suscetível de induzir ao erro o consumidor, mesmo através de omissões, tendo-se o erro como a falsa noção da realidade formada na mente do consumidor. Já a publicidade abusiva é a publicidade antiética, que fere a vulnerabilidade do consumidor, valores sociais básicos e a própria sociedade como um todo, o que legitima, inclusive, a atuação do Ministério Público Estadual e Federal e das Associações de Defesa dos Consumidores (MARQUES, 2002, p. 676 e 680).

Não basta, contudo, no contexto da sociedade de consumo, que a publicidade não seja enganosa ou abusiva. Nessa linha, a publicidade deve ser também socialmente responsável, sem contribuir com o consumismo e com o processo de alienação.

Nesse ponto, também muito perigosa se mostra a técnica do merchandising clandestino, ou seja, inserido num contexto veiculado em programas de televisão ou cinema de forma a não ser percebido como publicidade, criando associações entre produtos ou serviços e personagens ou artistas de destaque, restringindo a capacidade crítica do consumidor (NUNES, 2013, p. 544-546).

O poder condicionante que a publicidade exerce no comportamento dos consumidores é reconhecido pelos próprios artigos $2^{\circ}$ e $7^{\circ}$, do Código de Autoregulamentação Publicitária, pelos quais "a publicidade exerce forte influência de ordem cultural sobre grandes massas da população", em razão do que, "todo anúncio deve ser preparado com o devido senso de responsabilidade social, evitando acentuar, de forma depreciativa, diferenciações sociais decorrentes do maior ou menor poder aquisitivo dos grupos a que se destina ou que possa 
eventualmente atingir" (MARQUES, 2002, p.679).

Nesse contexto, o que se nota é que a proibição à publicidade enganosa e abusiva, na forma como materializada no Código de Defesa do Consumidor (Lei 8.078/1990), embora seja positiva para a proteção do hipossuficiente, não aborda as questões de sustentabilidade, devendo ser incrementada no sentido de ampliar o papel da empresa no combate ao consumismo.

Essa publicidade deturpada pela sanha empresarial de obtenção de lucros estratosféricos, que não desrespeita os ditames do Código de Defesa do Consumidor, mas manipula os indivíduos no sentido do hiperconsumismo se completa, perfeitamente, com outro fenômeno, que se convencionou chamar de obsolescência programada, o qual representa, simultaneamente, um atentado à boa-fé objetiva, à função social e à função solidária da empresa.

Durante o Século XX, a expectativa de vida de um norte-americano, por exemplo, aumentou em 30 (trinta) anos, ao passo que, nos últimos 50 (cinquenta) anos, o tempo de vida dos bens duráveis, como geladeiras, torradeiras e máquinas de lavar louças, diminuiu entre 3 (três) e 7 (sete) anos. $\mathrm{O}$ alto desenvolvimento da tecnologia em todo esse período torna contraditória a "involução" de tais produtos, a menos que se perceba que se trata de uma medida proposital e pensada no intuito de incrementar o aumento das suas vendas, como se, em verdade, já nascessem projetados para o lixo (BOTSMAN; ROGERS, 2011, p. 31).

Essa é a dinâmica da obsolescência programada. A ideia inicial da qual se originou o conceito de obsolescência programada remete ao ano de 1925, quando os principais fabricantes de lâmpadas da Europa e dos Estados Unidos, formadores do cartel Phoebus, decidiram reduzir o tempo de duração de suas lâmpadas de 2.500 (duas mil e quinhentas) para 1.000 (mil) horas, visando o incremento do lucro das indústrias filiadas. Foi em virtude da crise de 1929, todavia, que dito conceito viria a ser criado, pelo norte-americano Bernard London, um investidor imobiliário que defendia uma vida útil mais reduzida para os produtos impulsionaria a economia em colapso à época (BRAGA, 2012).

Considerada radical para a época, a ideia de London só foi colocada em prática na década de 1950, pelo designer industrial Brooks Stevens, profissional da área de desenvolvimento de produtos, que, defendendo a obsolescência programada, argumentava que o consumidor era livre para comprar ou não os produtos, independentemente da duração dos mesmos. Tal situação, aliada ao desenvolvimento da publicidade, todavia, acaba interferindo no estilo de 
vida do consumidor, que deixa de comprar por necessidade para consumir por hábito (BRAGA, 2012).

A obsolescência programada tornou a sociedade moderna em viciada em produtos novos, o que a sociologia denomina de "neofilia", ao contrário das sociedades pré-modernas, que desconfiavam do novo. A "moda" no período medieval, por exemplo, pouco mudou ao longo de mil anos, sendo o vestuário considerado apenas uma questão de necessidade. Em conclusão, pode-se afirmar que a obsolescência foi desenvolvida não apenas para o produto, mas também para as nossas mentes, no intuito de intencionalmente nos manter constantemente insatisfeitos (BOTSMAN; ROGERS, 2011, p. 28-30).

O documentário "Comprar, tirar, comprar", da diretora Cosima Dannoritzer, disponível gratuitamente na Internet, é comumente citado quando se trata da matéria da obsolescência programada, para ilustrar como a indústria tem trabalhado, nos últimos 100 (cem) anos, para, de forma planejada, induzir o consumo através da oferta de produtos de durabilidade menor.

Tais práticas, no contexto da sociedade de consumo, mostram-se extremamente preocupantes e merecem a atenção do direito, no intuito de se buscar alternativas para além do que está previsto no Código de Defesa do Consumidor, com lastro no princípio da solidariedade social, principalmente no que tange ao tema da publicidade, a qual deve estar presente nos negócios, mas sem o caráter de manipulação consumista.

É importante frisar que o Projeto do novo Código Comercial, de número 1572/2011, visa promover um resgate dos princípios específicos desta área, fazendo referência expressa, inclusive, à função social da empresa, em seu artigo $4^{\circ}$, onde se lê: "São princípios gerais informadores das disposições deste Código: I - liberdade de iniciativa; II - liberdade de competição; e III - função social da empresa".

Em seu artigo $7^{\circ}$, o citado projeto vai além e especifica parâmetros para que se possa aferir a função social, ao dispor: "a empresa cumpre sua função social ao gerar empregos, tributos e riqueza, ao contribuir para o desenvolvimento econômico, social e cultural da comunidade em que atua, de sua região ou do país, ao adotar práticas empresariais sustentáveis visando à proteção do meio ambiente e ao respeitar os direitos dos consumidores, desde que com estrita obediência às leis a que se encontra sujeita".

O mencionado dispositivo inegavelmente acerta ao tratar de forma dialética o intuito de lucro que deve existir na empresa e a necessidade 
de respeito ao interesse social, através da função social. As questões de sustentabilidade, todavia, conforme discorrido acima, têm ligação com o princípio da solidariedade social, caracterizando a função solidária da empresa, ou seja, um plus que deve ser estimulado pelo direito, inclusive pela via dos benefícios fiscais.

\section{CONCLUSÃO}

O desenvolvimento do sistema industrial e capitalista lastreado nesses ideais de liberdade e individualismo não se mostrou adequado como instrumento de proteção do ser humano, tendo provocado grave desequilíbrio e desigualdade econômico-social, desencadeando a valorização da noção de Estado social em substituição do modelo liberal.

O Estado social, agregando à esfera política do Estado liberal a dimensão econômica e social, bem como a preocupação com a efetividade dos direitos individuais e garantias fundamentais, é responsável pela introdução do conceito de socialidade no direito, pelo qual o interesse social prepondera sobre o pessoal.

Esse novo paradigma influenciou o atual Código Civil e promoveu uma revolução na concepção tradicional da empresa, com ênfase para o princípio da função social. A empresa assume, nesse prisma, uma segunda e nova dimensão, na qual se visa garantir o equilíbrio entre interesses privados e interesses sociais.

Todavia, contextualizando o princípio da função social da empresa na realidade atual da sociedade de consumo, nota-se que não bastam os atuais instrumentos de proteção, como a ingerência estatal no mercado de capitais, através da CVM, a desconsideração da personalidade jurídica e a proibição da publicidade enganosa.

É preciso que se imponha às empresas, com lastro no princípio da solidariedade social, uma atividade socialmente mais responsável, impedindoas, através de maiores limitações à publicidade, de estimularem o jogo das diferenças entre os indivíduos, o que opera na esfera dos estilos de vida, contribuindo para o crescimento do consumismo e da alienação radical.

\section{REFERÊNCIAS}

BAUDRILLARD, Jean. A sociedade de consumo. São Paulo: Edições 70, 
2010.

BAUMAN, Zygmund. Vida liquida. Trad. Carlos Alberto Medeiros. Rio de Janeiro: Jorge Zahar, 2007.

BITELI, Marcos. Da função social para a responsabilidade da empresa. In: VIANA, Rui Geraldo Camargo; NERY, Rosa Maria de Andrade (orgs.). Temas atuais de direito civil na Constituição Federal. São Paulo: Revista dos Tribunais, 2000. p. 229-276.

BONAVIDES, Paulo. Do Estado liberal ao Estado social. 3 ed. Rio de Janeiro: FGV, 1972.

BOTSMAN, Rachel; ROGERS, Roo. O que é meu é seu: como o consumo colaborativo vai mudar o nosso mundo. Trad. Rodrigo Sardenberg. Porto Alegre: Bookman, 2011.

BRAGA, Júlia. Obsolescência programada: o consume exacerbado e o esgotamento de fontes naturais, 2012.Disponível em: $<$ http://www.goethe. de/ins/br/lp/kul/dub/umw/pt10282568.htm>. Acesso em: 14. set. 2014.

BRIZ, Jaime Santos. La contratación privada: sus problemas en el tráfico moderno. Madri: Montecorvo, 1966.

CARDOSO, Alenilton da Silva. Princípio da solidariedade: o paradigma ético do direito contemporâneo. São Paulo: Juarez de Oliveira, 2010.

CRETELLA JR.. Comentários à Constituição de 1988. 3 ed. rev. Rio de Janeiro: Forense, 1992. v.1.

DINIZ, Marcio Augusto de Vasconcelos. Estado social e o princípio da solidariedade. Nomos: Revista do Curso de Mestrado em direito da UFC. Fortaleza, v. 26, janeiro-junho, 2007. p. 171-185.

DINIZ, Maria Helena. Dicionário jurídico. São Paulo: Saraiva, 1998. v. 2-4. 
FEATHERSTONE, Mike. Cultura de consumo e pós-modernismo. Trad. Julio Assis Simões. São Paulo: Studio Nobel, 1995.

FERREIRA, Pinto. Sociabilidade. In: FRANÇA, R. Limongi (coord.). Enciclopédia Saraiva de direito. Saraiva, São Paulo, v. 69, p. 424-425, 1977.

GIDDENS, Anthony. Mundo em descontrole. Trad. Maria Luiza X. de A. Borges. Rio de Janeiro: Record, 2007.

GUEDES, Jefferson Carús. Função social das "propriedades": da funcionalidade primitiva ao conceito atual de função social. In: ALVIM, Arruda e al. (coord.). Aspectos controvertidos do novo Código Civil. São Paulo: Revista dos Tribunais, 2003. p. 343-360.

HEDEMMAN, J. W.. Tratado de derecho civil: derecho de obrigaciones. Trad. José Luis Diez Pastor e Manuel Gonzalez Enriquez. Madri: Revista de Derecho Privado, 1958. v. III.

JUSTEN FILHO, Marçal. Desconsideração da personalidade societária no direito brasileiro. São Paulo: Revista dos Tribunais, 1987.

\section{LASKI, Harold J. O liberalismo europeu (The rise of european}

liberalism). Trad. Álvaro Cabral. São Paulo: Mestre Jou, 1973.

LAUAND, Rodrigo Porto. A autonomia privada, o mercado de capitais e os poderes da Comissão de Valores Mobiliários In: LOTUFO, Renan (coord.). Cadernos de Direito Civil Constitucional. Curitiba, Juruá, n. 2, 2001. p. 227-263.

LIPOVETSKY, Gilles. A felicidade paradoxal: ensaio sobre a sociedade de hiperconsumo. Trad. Maria Lucia Machado. São Paulo: Companhia das Letras, 2007.

LÔBO, Paulo Luiz Netto. Direito civil: parte geral. São Paulo: Saraiva, 2009. 
. Princípios Contratuais. In: LÔBO, Paulo Luiz Netto e LYRA JÚNIOR, Eduardo Messias Gonçalves de (coord.). A teoria do contrato e o novo código civil. Recife: Nossa Livraria, 2003. p. 9-23.

\section{MARQUES, Cláudia Lima. Contratos no código de defesa do} consumidor: o novo regime das relações contratuais. 4. ed. rev., atual. e ampl.. São Paulo: Revista dos Tribunais, 2002.

. Sugestões para uma lei sobre o tratamento do superendividamento de pessoas físicas em contratos de crédito ao consumo: proposições com base em pesquisa empírica de 100 casos no Rio Grande do Sul. In: MARQUES, Cláudia Lima; CAVALLAZZI; Rosângela Lunardelli (Coord). Direitos do consumidor endividado: superendividamento e crédito. São Paulo: Revista dos Tribunais, 2006. p. 255-309.

NERY JUNIOR, Nelson. Contratos no Código Civil: apontamentos gerais. In: FRANCIULLI NETTO, Domingos e al. (coord.). O novo código civil: estudos em homenagem ao Prof. Miguel Reale. São Paulo: LTR, 2003. p. 398-444.

NUNES, Rizatto. Curso de direito do consumidor. 8 ed. rev. e atual..São Paulo: Saraiva, 2013.

PORTILHO, Fatima. Sustentabilidade ambiental, consumo e cidadania. 2. ed. São Paulo: Cortez, 2010.

REALE, Miguel. O projeto de código civil: situação atual e seus problemas fundamentais. São Paulo: Saraiva, 1986.

REQUIÃO, Rubens. Abuso de direito e fraude através da personalidade jurídica. Revista dos Tribunais. São Paulo, v. 803, p. 751-764, set. 2002.

. A co-gestão: a função social da empresa e o Estado de direito.

Revista Forense, São Paulo, n. 74, v. 262, p. 31-39, abr.-jun., 1978. RODRIGUES, Silvio. Direito civil: dos contratos e das declarações unilaterais da vontade. 27 ed. São Paulo: Saraiva, 2002. v. 3. 
SANTOS, Antonio Jeová Santos. Função social, lesão e onerosidade excessiva nos contratos. São Paulo: Método, 2002.

SILVA, De Plácido e. Vocabulário jurídico. Rio de Janeiro: Forense, 1963. v. II.

SILVA, José Afonso da. Comentário contextual à Constituição. 6. ed. atual., São Paulo: Malheiros, 2009.

SOARES-BAPTISTA, Rozália Del Gáudio. Sociedade do consumo e gestão de desejos: marcas e publicidade face à sustentabilidade. In: PIMENTA, Solange Maria et al. (coord.). Sociedade e consumo: múltiplas dimensões na contemporaneidade. Curitiba: Juruá, 2010. p. 363-378.

TASCHNER, Gisela. Cultura, consumo e cidadania. Bauru, SP: EDUSC, 2009.

TOMASEVICIUS FILHO, Eduardo. A função social da empresa. Revista dos Tribunais. São Paulo, v. 810, n. 92, p. 33-50, abr. 2003.

WALD, Arnoldo. O empresário, a empresa e o Código Civil. In: FRANCIULLI NETTO, Domingos e al. (coord.). O novo código civil: estudos em homenagem ao Prof. Miguel Reale. São Paulo: LTR, 2003. p. 838-855.

Como citar: SANTIAGO, Mariana Ribeiro; CAMPELLO, Livia Gaigher Bósio. Função social e solidária da empresa na dinâmica da sociedade de consumo. Scientia Iuris, Londrina, v. 20, n. 1, p.119-143, abr. 2016. DOI: 10.5433/2178-8189.2016v20n1p119. ISSN: 2178-8189.

Submetido em 28/09/2014

Aprovado em 25/01/2016 